\title{
FATIGUE RESISTANCE OF OCCLUSAL VENEERS CONSTRUCTED FROM DIFFERENT CAD/CAM MATERIALS WITH DIFFERENT OCCLUSAL THICKNESSES
}

\author{
Amira Mohamed Elsharkawy*
}

\begin{abstract}
Purpose: The purpose of the current study was to evaluate the effect of different CAD/CAM materials and different occlusal thicknesses on the fatigue resistance of occlusal veneers.

Materials and Methods: Thirty intact maxillary molars were cut occlusally $4.0 \mathrm{~mm}$ above the cemento-enamel junction (CEJ). All teeth were dispersed into 3 main groups $(n=10)$ rendering to the CAD/CAM materials tested; Lithium Disilicate (UP.Cad), Vita Suprinity (VS) and Vita Enamic (VE). Each group were further subdivided into 2 subgroups $(n=5)$ rendering to restoration thickness $(1.0$ and $1.5 \mathrm{~mm}$ ). The restorations were adhesively bonded. Samples were subjected to step fatigue resistance test. Assessment of fracture mode was evaluated by Digital microscope. Scanning electron microscope (SEM) was used for fractographic analysis.
\end{abstract}

Results: The highest fatigue resistance was recorded for VS followed by UP.CAD while the least mean value recorded with $\mathrm{VE}$, the difference between groups was statistically significant $(\mathrm{P}=0.0003<0.05)$ as indicated by two-way ANOVA. Occlusal veneers with $1.5 \mathrm{~mm}$ thickness recorded statistically significant higher fatigue resistance mean value than $1 \mathrm{~mm}$ for all tested materials, $(\mathrm{P}=0.0005<0.05)$ as indicated by two-way ANOVA. Most of the fractures were repairable patterns.

Conclusions: The material type and occlusal thickness changes significantly affected the fatigue resistance of occlusal veneers. The fatigue resistance of the tested CAD/CAM materials seems promising also in $1.00 \mathrm{~mm}$ occlusal thickness.

KEY WORDS: Occlusal veneers \# CAD/ CAM materials \# occlusal thickness \# Fatigue resistance.

\section{INTRODUCTION}

The developing area of interest is the minimally invasive dentistry to restore teeth, great aids accomplished with the adhesive concept and variety of recently introduced ceramic materials. Maximum conservation of tooth structure is a fundamental for preserving the equilibrium between biological, esthetic, and functional considerations. This conception could be used positively with occlusal veneers.

\footnotetext{
* Associate Professor, Fixed Prosthodontics, Faculty of Dentistry, $6^{\text {th }}$ of October University, Giza, Egypt
} 
Dental attrition is often detected when a considerable loss of dental tissue has taken place..$^{(1)} \mathrm{Re}$ storative managements of this severely worn dentition were conventionally performed using inlays, onlays, elective tooth devitalization and multiple full-coverage restorations. ${ }^{(2)}$ Some of these methods can be very aggressive. Consequently, the development towards the less invasive treatment should be the first choice, as they conserve the dental tissue and pulp vitality. ${ }^{(2)}$

Occlusal veneers are modern extra coronal conservative restorations considered as a substitute solution for restoring vertical dimension in considerable occlusal tooth loss due to parafunctional habit or progressive physiological processes. The standard recommendation for ceramics restoration thickness is 1.5 to $2.0 \mathrm{~mm} .{ }^{(3)}$ However, the development of stronger materials as zirconia reinforced lithium silicate ceramics and the CAD/CAM technology, together with innovative adhesive technology such as immediate dentin sealing, have encouraged the introduction of thinner designs.

Amongst CAD/CAM materials; reinforced ceramics, the most common is monolithic lithium disilicate which have the necessary strength and esthetics. However, fracture properties of these materials, and their fabrication options greatly affected the possibility of occlusal veneer construction in thin conservative preparations. Recent advances in CAD/CAM materials are offering new options for restoration of severely worn dentition where space is limited. ${ }^{(4)}$

A novel CAD/CAM ceramic hybrid material has been technologically advanced by polymer infiltration into a porous ceramic network, (PIC) (Vita Enamic, Vident, Brea, CA, USA). ${ }^{(5)}$ This material has a microstructure similar to a natural tooth consists of a polymer-infiltrated ceramic network material and has mechanical properties that fall between those of porcelains and resin composites. ${ }^{(6)}$ On the other hand, the mechanical performance of polymeric materials needs to be further investigated compared with ceramics.

Zirconia-reinforced lithium silicate (ZLS) ceramics are a recent innovative type of hybrid CAD/ CAM ceramics that have been industrially advanced such as (e.g. Celtra Duo, Vita Suprinity). This glass ceramic material is augmented with Zirconia (10\%) into the lithium silicate glass matrix achieve to be more translucent and has higher flexural strength values similar to lithium disilicate. ${ }^{(6)}$ So it is mandatory to study its mechanical properties to see if this material would replace the monolithic Lithium disilicate - CAD ceramic material in restoring posterior dentition, since these region exhibit occlusal forces beyond Lithium disilicate - CAD strength. ${ }^{(7)}$

Regards to the importance of dental tissues conservasion; it is substantial to assess the fatigue resistance of reduced thickness of occlusal veneers fabricated from different ceramic materials. Thus, the purpose of the current study was to evaluate the effect of different CAD/CAM ceramic materials (UP.Cad, Vita Suprinity and Vita Enamic) with two different thicknesses $(1.00 \mathrm{~mm}$ and $1.5 \mathrm{~mm})$ on the fatigue resistance of teeth treated with occlusal veneers. The null hypothesis of this study was: The fatigue resistance of the posterior bonded occlusal veneers would not be affected by different ceramic types and occlusal thickness.

\section{MATERIALS AND METHODS}

\section{Sample size estimation}

Based on previous work ${ }^{(8)}$ sample size of (5) in each group has a $80 \%$ power to detect a difference between means of 354.90 with a significance level (alpha) of 0.05 (two-tailed) and 95\% confidence intervals. In $80 \%$ (the power) of those experiments, the $\mathrm{P}$ value will be less than 0.05 (two-tailed) so the results will be deemed "statistically significant". In the residual $20 \%$ of the tests, the difference between means will be deemed "not statistically significant". Report created by Graph Pad Stat Mate 2.00. 


\section{Sample fabrication}

Thirty extracted human maxillary first molars, which were caries and defects free. Extracted teeth were collected from Oral Surgery Department, Faculty of Dentistry, Cairo University. A digital caliper was used to confirm the comparable dimensions of selected teeth; the distance between the height of contours of buccal and lingual surfaces was $(12 \pm 2 \mathrm{~mm})$, while the mesio-distal dimensions were $(10 \pm 4 \mathrm{~mm})$ at (CEJ) level. Tissues and calculus deposits were removed with an ultrasonic scaler; the teeth were kept in distilled water at room temperature. Molars were inserted in epoxy resin (Chemapoxy resin, CMB chemicals, Egypt) blocks using round plastic rings as molds. Dental surveyor was used for centralizing the molars vertically up to $2 \mathrm{~mm}$ under CEJ in the plastic rings during epoxy resin blocks construction similar to bone level. All teeth received standardized preparation similar to worn out occlusal surfaces by means of a diamond saw in (ISOMET 4000, Buehler, and Lake Bluff, IL, USA). Coronal tooth structure was detached; $4.0 \mathrm{~mm}$ above CEJ measured with a digital caliper exposing peripheral enamel and central bare dentin. ${ }^{(9)}$ Two indentations were prepared in the mesial and distal enamel margins using a high-speed round-ended diamond rotary bur (\#ZR 850 FG.01, Komet USA) to enable accurate occlusal veneers seating during cementation. Microcracks and pulpal exposures were checked after each preparation. The prepared teeth were haphazardly divided into three main groups $(n=10)$ according to the CAD/CAM ceramic materials used for occlusal veneers production as follows; Group I: molars restored with lithium disilicate occlusal veneers (Up.Cad, Shenzhen Upcera Dental Technology Co, High-tech Industry Park, Nanshan District, Shenzhen, Guangdong, China ). Group II (VS): molars restored with zirconia lithium silicate occlusal veneers (Vita Suprinity, Vita Zahnfabrik H. Rauter GmbH \& Co.KG), and Group III (VE): molars restored with Vita Enamic occlusal veneers (Vita Zahnfabrik, Bads"ackingen, Germany). Tested materials Composition and their Producers are described in Table (1).

TABLE (1) Tested materials Composition and their Producers:

\begin{tabular}{|c|c|c|c|}
\hline Material & Specification & Manufacturer & Chemical Composition \\
\hline UP. Cad & $\begin{array}{l}\text { Lithium disilicate } \\
\text { glass ceramics }\end{array}$ & $\begin{array}{l}\text { Shenzhen Upcera } \\
\text { Dental Technology Co, } \\
\text { High-tech Industry Park, } \\
\text { Nanshan, China }\end{array}$ & $\begin{array}{l}\mathrm{Li} 2 \mathrm{O}(11 . \%-19 \%), \mathrm{SiO} 2(57 \%-80 \%), \mathrm{P} 2 \mathrm{O} 5(0.0 \%- \\
11.0 \%), \mathrm{K} 2 \mathrm{O}(0.0 \%-13 \%) \mathrm{ZrO} 2(0.0 \%-8.0 \%), \mathrm{ZnO} \\
(0.0 \%-8.0 \%), \mathrm{MgO}(0.0-5.0), \mathrm{A} 12 \mathrm{O} 3(0.0 \%-5 . \%) \text {, and } \\
\text { coloring oxides }(0.0-8.0)\end{array}$ \\
\hline Vita Suprinity & $\begin{array}{l}\text { zirconia reinforced } \\
\text { lithium silicate glass } \\
\text { ceramic material }\end{array}$ & $\begin{array}{l}\text { Vita Zahnfabrick, Bad } \\
\text { Säckingen, Germany }\end{array}$ & $\begin{array}{l}\mathrm{SiO} 2, \mathrm{Li} 2 \mathrm{O}, \mathrm{K} 2 \mathrm{O}, \mathrm{P} 2 \mathrm{O} 5, \mathrm{~A} 12 \mathrm{O} 3, \mathrm{ZrO} 2, \mathrm{CeO} 2, \mathrm{La} 2 \mathrm{O} 3 \\
\text { Pigments }\end{array}$ \\
\hline Vita Enamic & $\begin{array}{l}\text { Polymer-infiltrated } \\
\text { ceramics }\end{array}$ & $\begin{array}{l}\text { VITA Zahnfabrik, Bad } \\
\text { Säkingen, Germany }\end{array}$ & $\begin{array}{l}\text { Ceramic component: } \mathrm{A} 12 \mathrm{O} 3(20-23), \mathrm{SiO} 2(58-63) \\
\mathrm{K} 2 \mathrm{O}(4-6), \mathrm{Na} 2 \mathrm{O}(6-11), \mathrm{B} 2 \mathrm{O} 3(0.5-2), \mathrm{CaO}(<1) \text { and } \\
\mathrm{TiO} 2(<1) \text { Polymer component: methacrylate polymer } \\
\text { Ceramic to polymer ratio; } 86 \%-14 \% \text { by weight }\end{array}$ \\
\hline RelyX Unicem & $\begin{array}{l}\text { Dual cure Self- } \\
\text { adhesive resin cement }\end{array}$ & 3M, GmbH, Germany & $\begin{array}{l}\text { Powder: Glass powder, initiator, Silica, Substituted } \\
\text { pyrimidine, Calcium hydroxide, Peroxy compound, } \\
\text { Pigment. Liquid: Methacrylated phosphoric ester, } \\
\text { Dimethacrylate, Acetate, Stabiliser, and initiator. }\end{array}$ \\
\hline
\end{tabular}




\section{Occlusal veneers fabrication}

Occlusal veneers were constructed with CAD/ CAM technology using Exocad software (2.2 Valletta). The prepared teeth surfaces were scanned with CAD scanner (Medit extraoral scanner T510). All images were transferred to the Exocad software for designing. Each group was further subdivided according to the thickness of the constructed occlusal veneer into two subgroups $(n=5)$ as follows; Subgroup (1mm): molars received thin occlusal veneers with $1 \mathrm{~mm}$ thickness. Subgroup $(1.5 \mathrm{~mm})$ : molars received occlusal veneers with $1.5 \mathrm{~mm}$ thickness (measured from the central groove). All restorations were constructed with standardized anatomical occlusal veneers; restoration thicknesses were adjusted and standardized virtually in the software, the angle between the cusps was $145^{\circ}$ in both groups. ${ }^{(10)}$ (Figure 1) Virtual die spacer was selected $(50 \mu \mathrm{m})$ and standardized in all samples. Occlusal veneers were milled in a 5-axis wet milling machine (CORiTecImes icore 250i). The UP.Cad occlusal veneers were milled from lithium metasilicate blocks (Up. Cad, Shenzhen Upcera Dental Technology Co, High-tech Industry Park, Nanshan District, Shenzhen, Guangdong, China) after milling step, occlusal veneers were transferred to a ceramic furnace for crystallization for 30 minutes at $850{ }^{\circ} \mathrm{C}$ (Programat p3010, Ivoclar Vivadent). After crystallization, the sprues were detached. Rubber cups were used for occlusal veneers polishing. Finally veneers were glazed at $700 \circ \mathrm{C}$. Vita Suprinity occlusal veneers were milled from Zirconium Lithium Silicate (ZLS) blocks (VITA Suprinity, VITA Zahnfabrik H. Rauter GmbH \& Co.KG). Finally, in Programat p3010, Ivoclar Vivadent, occlusal veneers were fully crystallized and glazed. Polymer-infiltrated ceramics veneers were milled

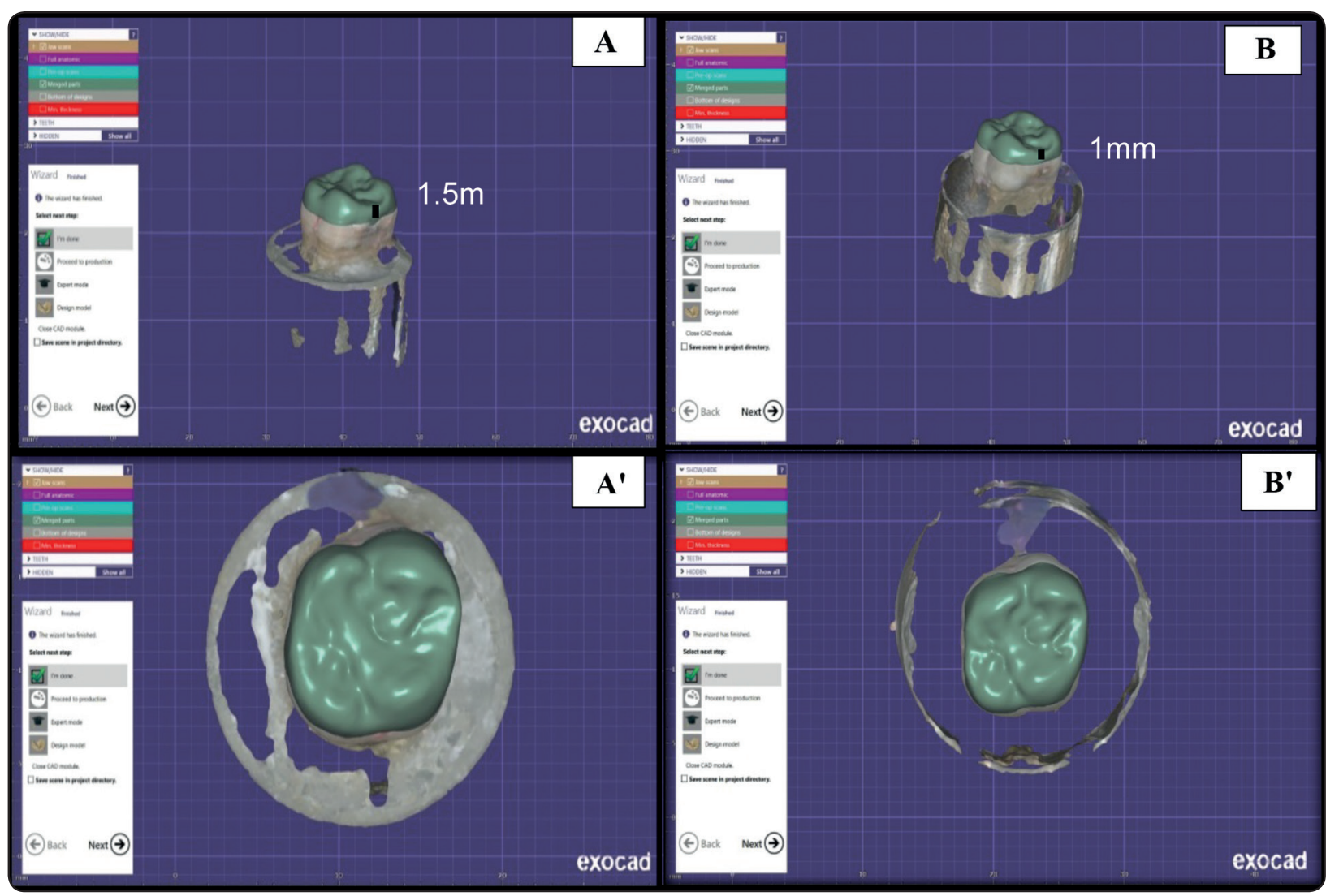

Fig. (1): Occlusal veneer designing. A: $1.5 \mathrm{~mm}$ thickness measurement in exocad software and its occlusal anatomy refining (A'). B: $1.00 \mathrm{~mm}$ thickness measurement in exocad software and its occlusal anatomy refining (B'). 
from Vita Enamic blocks (VITA Zahnfabrik, Bad Säkingen, Germany) then finished with rubber (Eve America; Naples, FL).

\section{Cementation of Occlusal veneers}

The occlusal veneers were checked for accurate seating. Pumice was used for cleaning the prepared teeth and washed with water. All occlusal veneers were cleaned with $99 \%$ isopropanol in an ultrasonic cleaner for 5 minutes. All UP. Cad and VS veneers were etched with Bisco Porcelain Etch with $10 \%$ hydrofluoric acid (BISCO, Illinois, U.S.A.) for 20 seconds, while VE veneers were etched for 60 seconds. Then all veneers were washed with water and dried with oil free air. All veneers were sialinated with silane coupling agent, (BISCO, Illinois, U.S.A.) for 60 seconds then air dried with oil free air for 5 seconds.

Phosphoric acid $37.5 \%$ (Ultra- Etch, Ultradent Products) was used for selectively etching enamel margins of all the prepared teeth, then rinsed for 10 seconds and dried. Using dual cure self-adhesive resin cement RelyX Unicem (3M, GmbH, Germany) (Table 1) occlusal veneers were cemented to their corresponding teeth. Each veneer was seated on the corresponding tooth using finger pressure then transferred to the custom-made cementation device to apply a constant load of $3 \mathrm{~kg}$ for 10 minutes. LEDcuring unit (Elipar, 3M ESPE, St Paul, Minnesota, USA), was used, all veneers were initially cured for 5 seconds with a light intensity of $1400 \mathrm{~mW} / \mathrm{cm}^{2}$ and at a $2.0 \mathrm{~mm}$ distance, dental probe was used for all excess cement removal and light-cured from each surface for $30 \mathrm{~s}$. Then all samples were transferred to distilled water 24 hours before fatigue testing.

\section{Fatigue resistance test}

\section{Step-stress accelerated life testing (SSALT)}

Cyclic Fatigue failure test were completed in a material testing machine (Instron, Model 3345,
Instron, USA) which was set to apply compressive force with a round $5 \mathrm{~mm}$ diameter stainless steel stylus onto the restored tooth. The stylus tip was placed above the central fossa to make tripodization of contacts, the load was applied occlusally and dynamically at a frequency of $2 \mathrm{~Hz}$, in water bath at room temperature similar to the intraoral circumstances, each sample were exposed to a suggested number of cycles (1000 cycle) with a progressive increasing in stress level, until sample failure. The beginning stress level was less than the estimated material's fatigue limit by (30-60\% of single load to failure). ${ }^{(1)}$ A sudden drop in the load curve, confirms the sample failure. The following equation was used to calculate the fatigue failure load for each sample. ${ }^{(11)}$

$$
\sigma_{\mathrm{e}}=\sigma_{0}+\Delta \sigma(\mathrm{Nfail} / \mathrm{Nlife})
$$

Where $\sigma e$ is the maximum fatigue load corresponding to $\mathrm{N}$ Life cycles, $\sigma 0$ is the previous maximum fatigue load that did not result in failure, $\Delta \sigma$ is the step increase in maximum fatigue load, NFail the cycles to failure at the fatigue stress and the $\mathrm{N}$ Life defined cyclic fatigue life.

\section{Examination of fractured samples}

All samples in the test groups after fatigue failure test were viewed visually and by digital microscope under 35X magnification. USB digital-microscope (U500x Digital Microscope, Guangdong, China) was used and the images were captured and transferred to a IBM personal computer equipped with the Image-tool software (Image J 1.43U, National Institute of research, Giza, Egypt) to determine failure mode pattern and the restorability of residual tooth structure. Evaluation standard criteria were classified according to previous study ${ }^{(12)}$ : Type I: extensive cracks or fracture in the restoration only (repairable), Type II: fracture including both the restoration and tooth structure above CEJ (repairable), and Type IV: longitudinal fracture of the restoration and tooth (catastrophic). 


\section{Scanning Electron Microscope analysis}

The representative specimens were randomly selected and examined by scanning electron microscopy (SEM) for fractographic analysis. Prior to scanning, all samples were washed with alcohol in an ultrasonic bath (BioSonic UC50D, Whaledent, USA) for $10 \mathrm{~min}$ and coated with gold. Specimen holders were used for samples fixation using the SEM vacuum-quality adhesive. Superficial image was scanned using (SEM; JEOL JSMT 20. Japan). SEM settings were: $10.1 \mathrm{~mm}$ working distance, inlens detector, excitation voltage of $30 \mathrm{KV}, 90 \mathrm{x}, 400 \mathrm{x}$, 600x magnification and $1 \mathrm{~nm}$ resolution. Different magnifications were used to detect the characteristic marks of the crack origin and its propagation direction. Finally, photographs were recorded and fractographic analyses were completed according to the ceramic materials description in previous studies. ${ }^{(13,14)}$

\section{RESULTS}

Data were collected from the three groups, organized via Excel of Microsoft (version 365). The data got using the accelerated fatigue failure load and survival table for each load to compare fatigue resistance between the groups. The statistical difference between the three groups was verified using One-way ANOVA test while student t-test was used to verify the significant difference between thicknesses. The influence of each variable (material and thickness) was detected by Twoway ANOVA test. Chi square test was used for comparing Failure mode analysis (\%). Graph-Pad Instat statistics software (version 3.06) for Windows was used for Statistical analysis. P values $<0.05$ were statistically significant in all tests. Sample size ( $n=5 /$ group) was large enough to detect large effect sizes for main effects and pair-wise comparisons, with the satisfactory level of power set at $80 \%$ and a 95\% confidence level.

Fatigue resistance results; mean values, standard deviation (SD) and confidence intervals (low and high) for tested groups with different thicknesses are tabulated in (Table 2) and displayed graphically in (Figure 2).

\section{$1 \mathrm{~mm}$ occlusal veneers thickness:}

The highest fatigue resistance mean $\pm \mathrm{SD}$ values were registered for Up.Cad group; (1313.2 24.7 N) followed by VSuprinity group mean \pm SD values; $(1253.8 \pm 8.5 \mathrm{~N})$ while; the least mean $\pm \mathrm{SD}$ values were verified for VEnamic; $(991.5 \pm 129.7$ N). The difference among groups was statistically significant as revealed by ANOVA test $(\mathrm{p}=<0.0001<0.05)$. Tukey's post-hoc test showed non-significant $(\mathrm{p}>0.05)$ difference between (UP.Cad and VSuprinity)

\section{$1.5 \mathrm{~mm}$ occlusal veneers thickness:}

The highest fatigue resistance mean \pm SD values were registered for VSuprinity group; (2192.6 $\pm 546.2 \mathrm{~N})$ followed by UP.Cad group mean \pm SD values; $(1558 \pm 52.6 \mathrm{~N})$ while; the lowest mean \pm SD values were documented for VEnamic ; $(1133.8 \pm 31.8 \mathrm{~N})$. The difference among groups was statistically significant as revealed by ANOVA test $(\mathrm{p}=0.0007<0.05)$. Tukey's post-hoc test showed non-significant $(\mathrm{p}>0.05)$ difference between (UP . $C A D$ and $V$ enamic)

\section{$1 \mathrm{~mm}$ vs. $1.5 \mathrm{~mm}$ occlusal veneers thickness for each material}

- With UP.Cad group, $1.5 \mathrm{~mm}$ thickness Subgroup recorded statistically significant $(\mathrm{p}=<0.0001<0.05)$ higher fatigue resistance mean value; $(1558 \pm 52.6 \mathrm{~N})$ than $1 \mathbf{~ m m}$ thickness subgroup; $(1313.2 \pm 24.7 \mathrm{~N})$ as indicated by paired t-test. Table (2) and Figure (2).

- With VSuprinity group, $1.5 \mathrm{~mm}$ thickness subgroup recorded statistically significant $(\mathrm{p}=0.0049<0.05)$ higher fatigue resistance mean value; $(2192.6 \pm 546.2 \mathrm{~N})$ than $\mathbf{1 ~} \mathbf{~ m m}$ thickness subgroup; $(1253.8 \pm 8.5 \mathrm{~N})$ as indicated by paired t-test. Table (2) and Figure (2). 
TABLE (2) Descriptive statistics of fatigue failure load test results (N) (mean \pm SD) between all groups as function of occlusal veneer thickness.

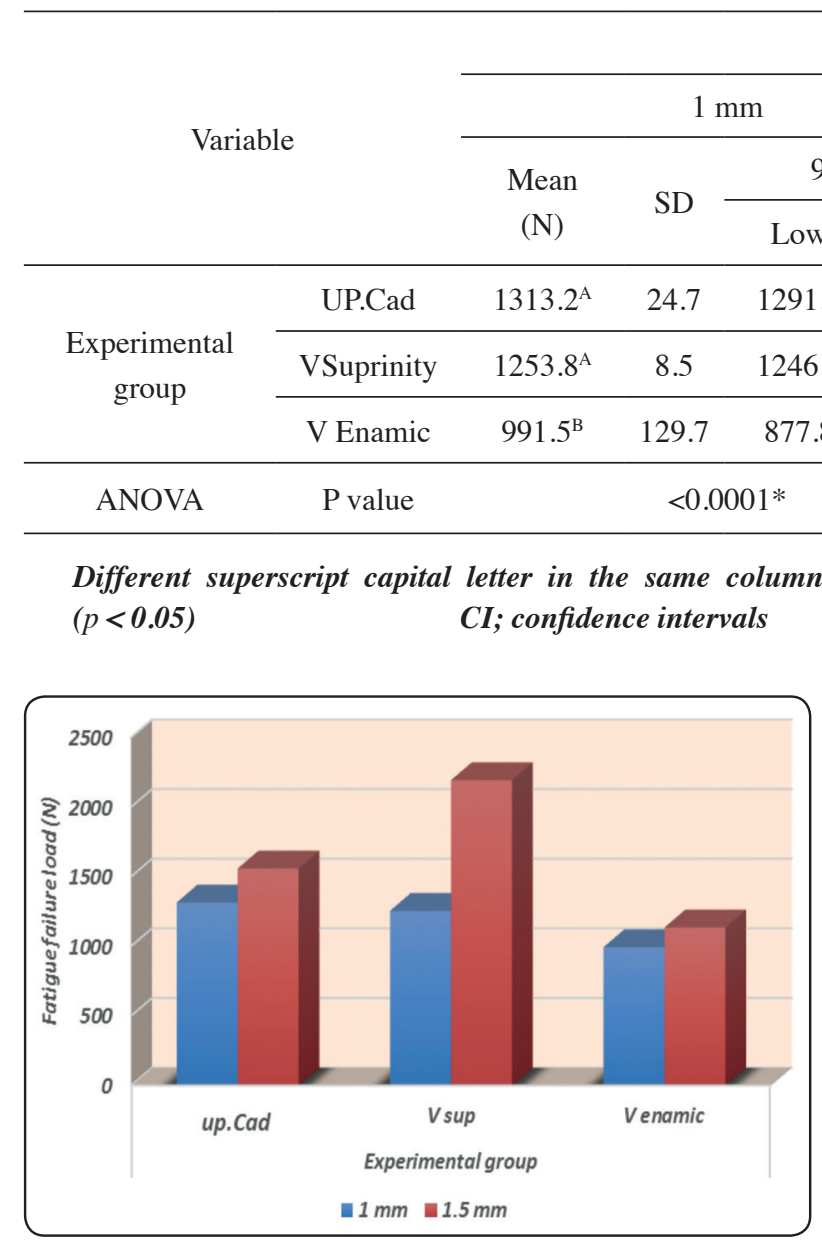

Fig. (2): Column diagram displaying fatigue failure load mean values $(\mathrm{N})$ for all groups as function of occlusal veneer thickness.

- With VEnamic group, $1.5 \mathrm{~mm}$ thickness subgroup recorded statistically significant $(\mathrm{p}=0.0443<0.05)$ higher fatigue resistance mean value; $(1133.8 \pm 31.8 \mathrm{~N})$ than 1 mm thickness subgroup; $(991.5 \pm 129.7 \mathrm{~N})$ as indicated by paired t-test. Table (2) and Figure (2).

\section{Effect of material group on fracture resistance}

Irrespective to restoration thickness, totally, it was found that the highest fatigue resistance was recorded for VS followed by UP.Cad while the lowest fatigue resistance mean value recorded with V. Enamic, the difference between groups was statistically significant $(\mathrm{P}=0.0003<0.05)$ as indicated by two-way ANOVA.

\section{Effect of occlusal thickness on fracture resistance}

Regardless to material groups totally it was found that $1.5 \mathrm{~mm}$ occlusal thickness recorded statistically significant higher fatigue resistance mean value than $1 \mathrm{~mm}$ occlusal thickness the difference between thicknesses was statistically significant $(\mathrm{P}=0.0005<0.05)$ as indicated by twoway ANOVA.

\section{Failure mode analysis of the fractured samples}

Frequent distribution (\%) of failure mode analysis for all tested groups as function of material type and occlusal thickness was classified into three modes as observed by digital microscope are tabulated (Table 3) and illustrated (Figure 3). The most common failure patterns in VEnamic were repairable $(100 \%)$ and no catastrophic failures, these results were for both occlusal thicknesses.

Survival rate: Specimens survival rate recorded for all investigational groups as function of step load was tabulated and graphically drawn (Table 4, Figure 4) 
TABLE (3) Descriptive statistics of frequent distribution (\%) of failure mode analysis for all tested groups as function of thickness:

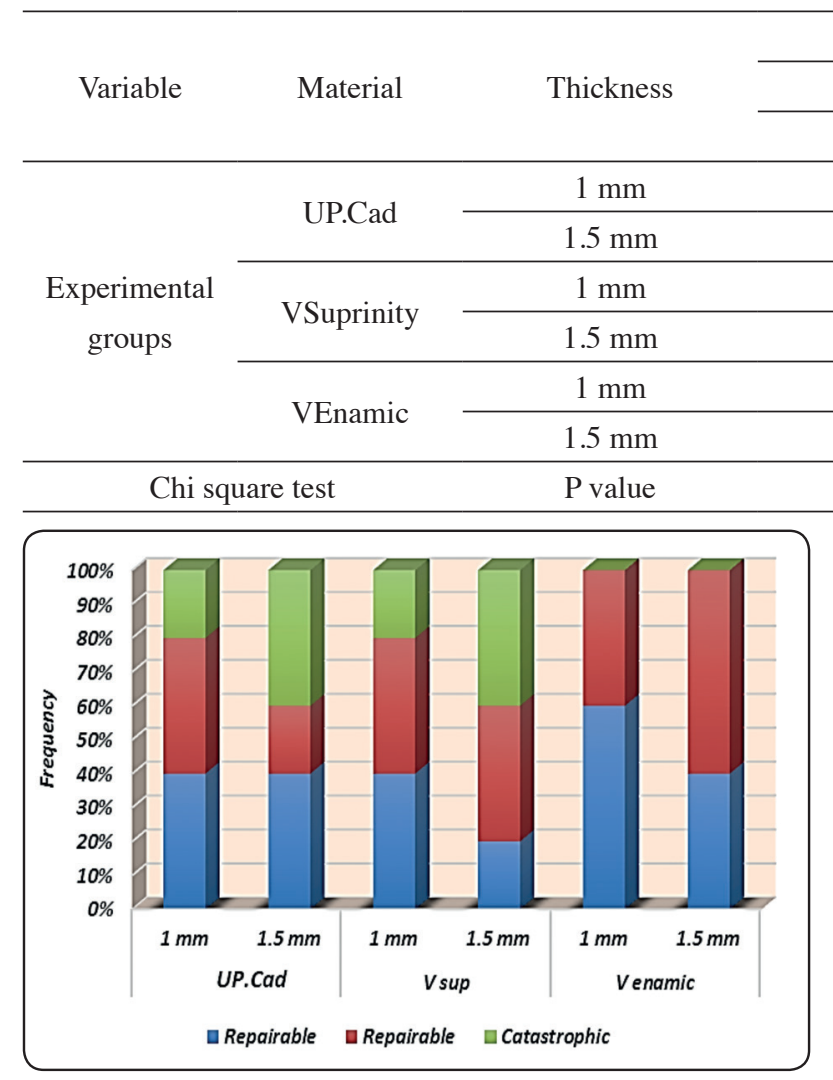

Fig. (3): Stacked column chart showing frequent failure Type (\%) for all groups as function of occlusal veneer thickness.

Regards to UP.Cad and VSuprinity occlusal veneers with (1mm occlusal thickness); the predominant failures were repairable $(80 \%)$ and $20 \%$ catastrophic whereas, the $1.5 \mathrm{~mm}$ occlusal thickness revealed $60 \%$ repairable and $40 \%$ catastrophic failures for both materials. The difference between groups regarding failure mode analysis was statistically significant as proved by Chi square test $(\mathrm{p}=<0.0001<0.05)$. Demonstrative samples from each failure mode are displayed in (Figure 5).

\section{Scanning Electron Microscope analysis (Failure pattern analysis)}

Regards to UP.Cad and VE occlusal veneers with both occlusal thicknesses $(1.00 \mathrm{~mm}$ and $1.5 \mathrm{~mm})$; the cracks originated in the area of loading contact occlusally propagated cervically. The hackles
Failure mode

\begin{tabular}{lcc}
\multicolumn{3}{c}{ Failure mode } \\
Rype I & Type II & Catastrophic \\
\hline$(40 \%)$ & $2(40 \%)$ & Type III \\
\hline$(40 \%)$ & $1(20 \%)$ & $2(20 \%)$ \\
\hline$(40 \%)$ & $2(40 \%)$ & $1(20 \%)$ \\
\hline$(20 \%)$ & $2(40 \%)$ & $2(40 \%)$ \\
\hline$(60 \%)$ & $2(40 \%)$ & $0(0 \%)$ \\
\hline$(40 \%)$ & $3(60 \%)$ & $0(0 \%)$ \\
\hline
\end{tabular}

$2(40 \%) \quad 3(60 \%)$

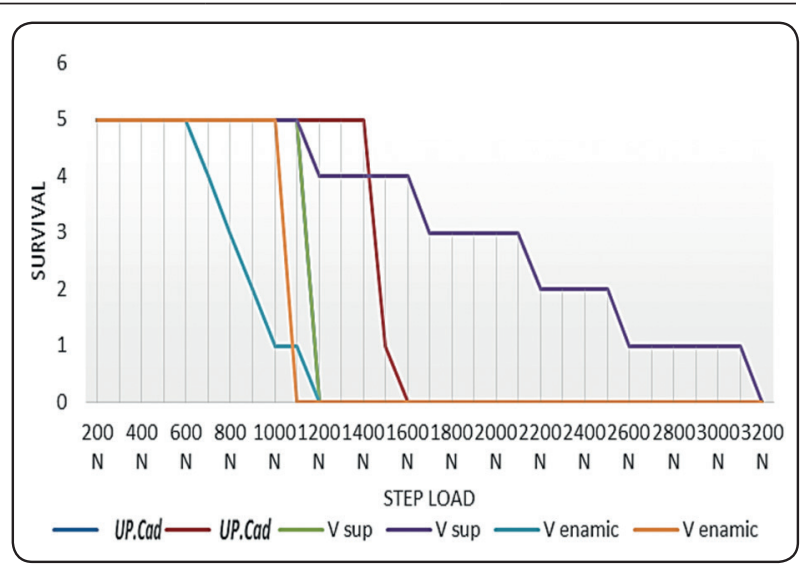

Fig. (4): Linear curves display survival rate of all investigational groups.

observed below the area of cracks starting and perpendicular to the crack origin, propagated deeply into the inner surface following the applied loads. The arrest lines were present in the form of ridges on the fracture surfaces, indicating the joining of the cracks at this intersection (Figure 6,7). In the VE samples, the minor crack propagations were stopped inside the deep occlusal surface, proposing the possibility of crack limitation due to good damage tolerance; as shown in SEM (Figure 9, 10).

Regards to Vita Suprinity, the crack origins start near the interfaces between the occlusal veneer and cementation layer, these cracks propagated occlusally and proximally confirmed by compression curls and twisted hackle marks with bifurcations across the occlusal surface these results observed for both occlusal thicknesses $(1.00 \mathrm{~mm}$ and $1.5 \mathrm{~mm})$. 
TABLE (4) Survival rate of specimens documented for all investigational groups as function of occlusal veneer thickness at different step load.

\begin{tabular}{|c|c|c|c|c|c|c|c|}
\hline \multirow{3}{*}{ 列 } & \multirow{3}{*}{ Variable } & \multicolumn{6}{|c|}{ Experimental group } \\
\hline & & \multicolumn{2}{|c|}{ UP.CAD } & \multicolumn{2}{|c|}{$V S$} & \multicolumn{2}{|c|}{$V E$} \\
\hline & & $1 \mathrm{~mm}$ & $1.5 \mathrm{~mm}$ & $1 \mathrm{~mm}$ & $1.5 \mathrm{~mm}$ & $1 \mathrm{~mm}$ & $1.5 \mathrm{~mm}$ \\
\hline \multirow{31}{*}{ 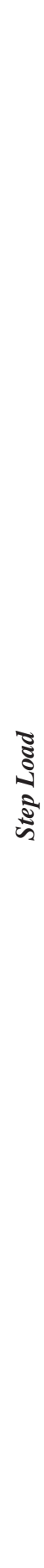 } & $200 N$ & 5 & 5 & 5 & 5 & 5 & 5 \\
\hline & $300 N$ & 5 & 5 & 5 & 5 & 5 & 5 \\
\hline & $400 N$ & 5 & 5 & 5 & 5 & 5 & 5 \\
\hline & $500 \mathrm{~N}$ & 5 & 5 & 5 & 5 & 5 & 5 \\
\hline & $600 N$ & 5 & 5 & 5 & 5 & 5 & 5 \\
\hline & $700 \mathrm{~N}$ & 5 & 5 & 5 & 5 & 4 & 5 \\
\hline & $800 \mathrm{~N}$ & 5 & 5 & 5 & 5 & 3 & 5 \\
\hline & $900 N$ & 5 & 5 & 5 & 5 & 2 & 5 \\
\hline & $1000 \mathrm{~N}$ & 5 & 5 & 5 & 5 & 1 & 5 \\
\hline & $1100 \mathrm{~N}$ & 5 & 5 & 5 & 5 & 1 & 0 \\
\hline & $1200 \mathrm{~N}$ & 0 & 5 & 0 & 4 & 0 & 0 \\
\hline & $1300 \mathrm{~N}$ & 0 & 5 & 0 & 4 & 0 & 0 \\
\hline & $1400 \mathrm{~N}$ & 0 & 5 & 0 & 4 & 0 & 0 \\
\hline & $1500 \mathrm{~N}$ & 0 & 1 & 0 & 4 & 0 & 0 \\
\hline & $1600 \mathrm{~N}$ & 0 & 0 & 0 & 4 & 0 & 0 \\
\hline & $1700 \mathrm{~N}$ & 0 & 0 & 0 & 3 & 0 & 0 \\
\hline & $1800 \mathrm{~N}$ & 0 & 0 & 0 & 3 & 0 & 0 \\
\hline & $1900 \mathrm{~N}$ & 0 & 0 & 0 & 3 & 0 & 0 \\
\hline & $2000 \mathrm{~N}$ & 0 & 0 & 0 & 3 & 0 & 0 \\
\hline & $2100 \mathrm{~N}$ & 0 & 0 & 0 & 3 & 0 & 0 \\
\hline & $2200 \mathrm{~N}$ & 0 & 0 & 0 & 2 & 0 & 0 \\
\hline & $2300 N$ & 0 & 0 & 0 & 2 & 0 & 0 \\
\hline & $2400 N$ & 0 & 0 & 0 & 2 & 0 & 0 \\
\hline & $2500 \mathrm{~N}$ & 0 & 0 & 0 & 2 & 0 & 0 \\
\hline & $2600 \mathrm{~N}$ & 0 & 0 & 0 & 1 & 0 & 0 \\
\hline & $2700 N$ & 0 & 0 & 0 & 1 & 0 & 0 \\
\hline & $2800 \mathrm{~N}$ & 0 & 0 & 0 & 1 & 0 & 0 \\
\hline & $2900 \mathrm{~N}$ & 0 & 0 & 0 & 1 & 0 & 0 \\
\hline & $3000 \mathrm{~N}$ & 0 & 0 & 0 & 1 & 0 & 0 \\
\hline & $3100 \mathrm{~N}$ & 0 & 0 & 0 & 1 & 0 & 0 \\
\hline & $3200 N$ & 0 & 0 & 0 & 0 & 0 & 0 \\
\hline
\end{tabular}




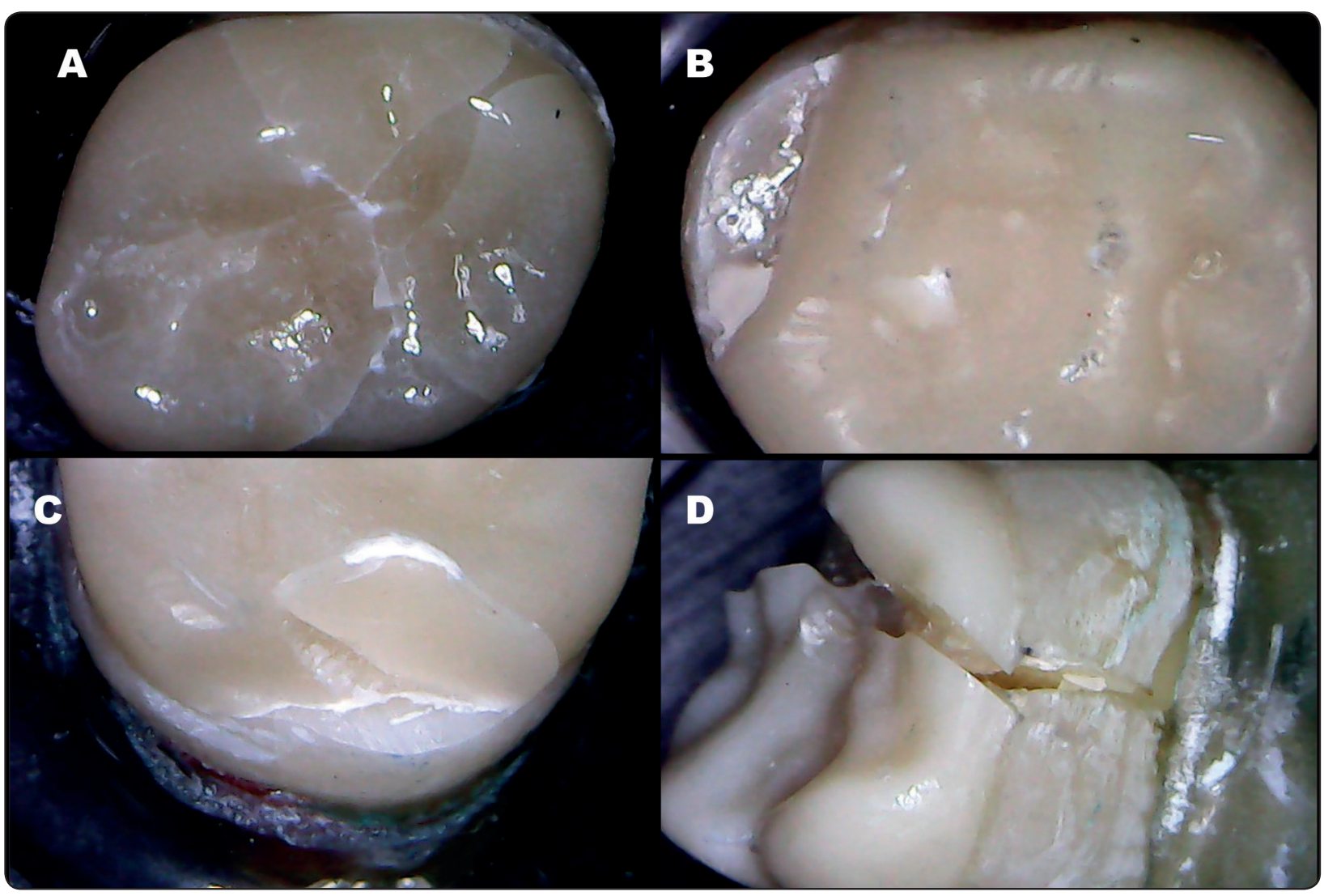

Fig. (5): Digital microscope photograph (35X) of the different failure patterns of the occlusal veneers.

A) Extensive crack in Up.Cad (1.00mm) occlusal veneer. (Repairable failure).

B) Fracture of the VS (1.5mm) occlusal veneer without fracture of the tooth. (Repairable failure).

C) Fracture of the VE (1.00mm) occlusal veneer with enamel chipping. (Repairable failure).

D) Longitudinal fracture of the restoration and tooth in VS $(1.5 \mathrm{~mm})$ occlusal veneer. (Catastrophic failure).

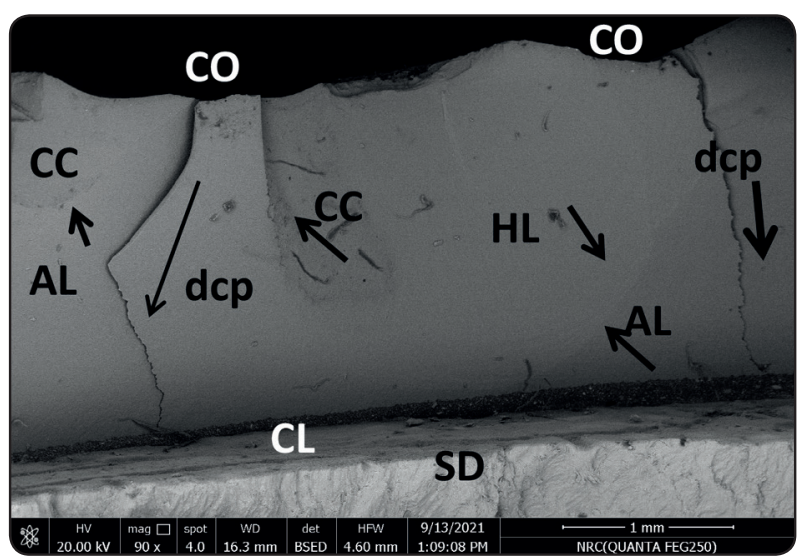

Fig. (6): SEM photograph of the fractured UP.CAD occlusal veneer with $1.5 \mathrm{~mm}$ occlusal thickness presenting cracks origins (CO) started occlusally and extended to the cementation surface, (dcp) direction of crack propagation. HL: hackle line confirming that the direction of crack propagation. AL: arrest line CC: compression curle. CL: cementation layer, SD: supporting die. 


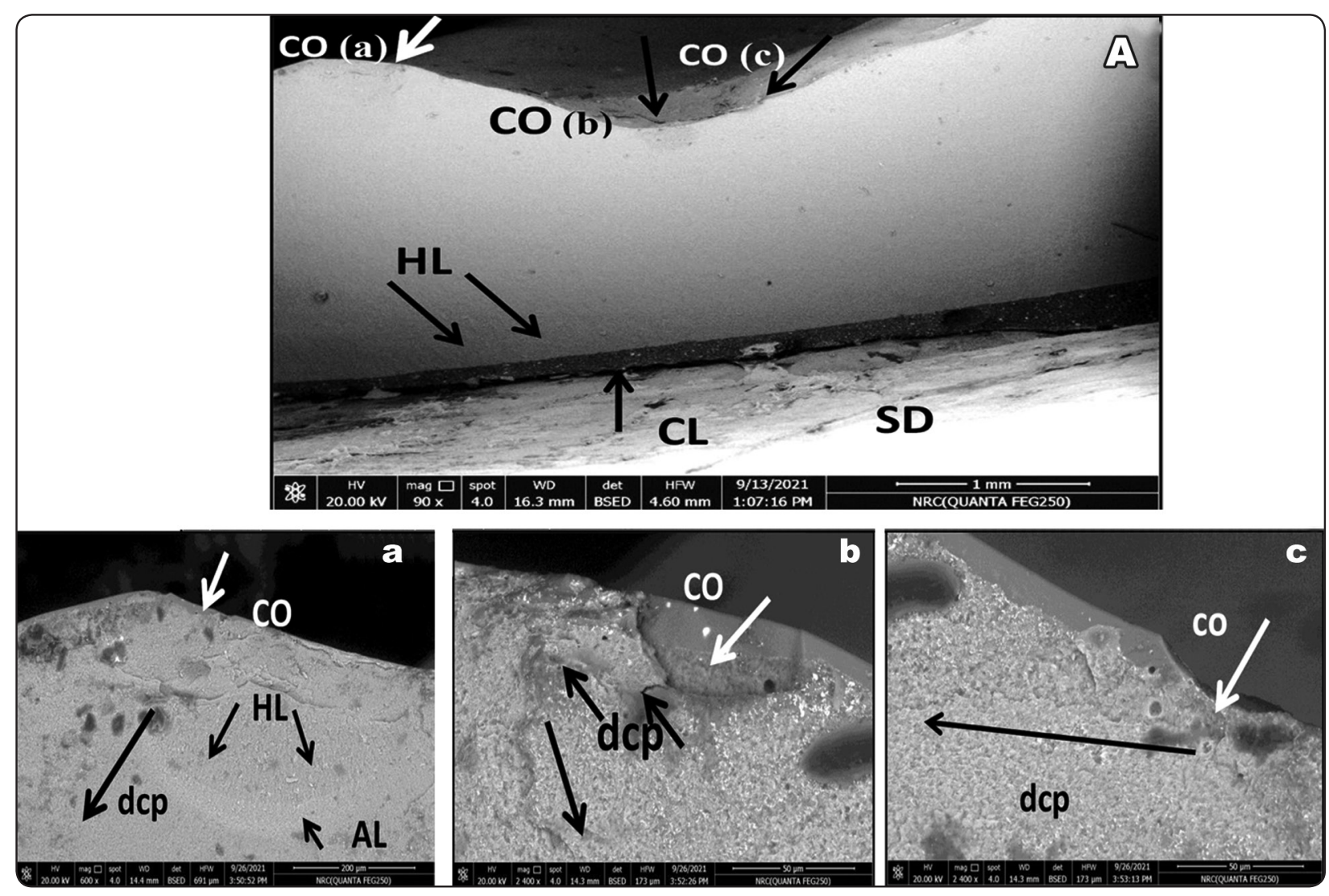

Fig. (7): (A) SEM images of the fractured surface of UP.CAD occlusal veneer (cohesive fracture) with 1 mm occlusal thickness showing the cracks origins (co) located on the occlusal surface (a), (b), (c). The black arrows point to the hackles (HL). CL: cementation layer, SD: supporting die:

Crack origin (a) (co): black arrows point to hackle lines (HL) perpendicular to the crack origin. AL: arrested line trying to stop the hackles, black arrow point to direction of crack propagation (dcp) to the cement line below.

Crack origin (b) (co): black arrows point to direction of crack propagation (dcp) to the cement line below. Crack origin (c) (co): black arrows point to direction of crack propagation(dcp) to the cement line below. 


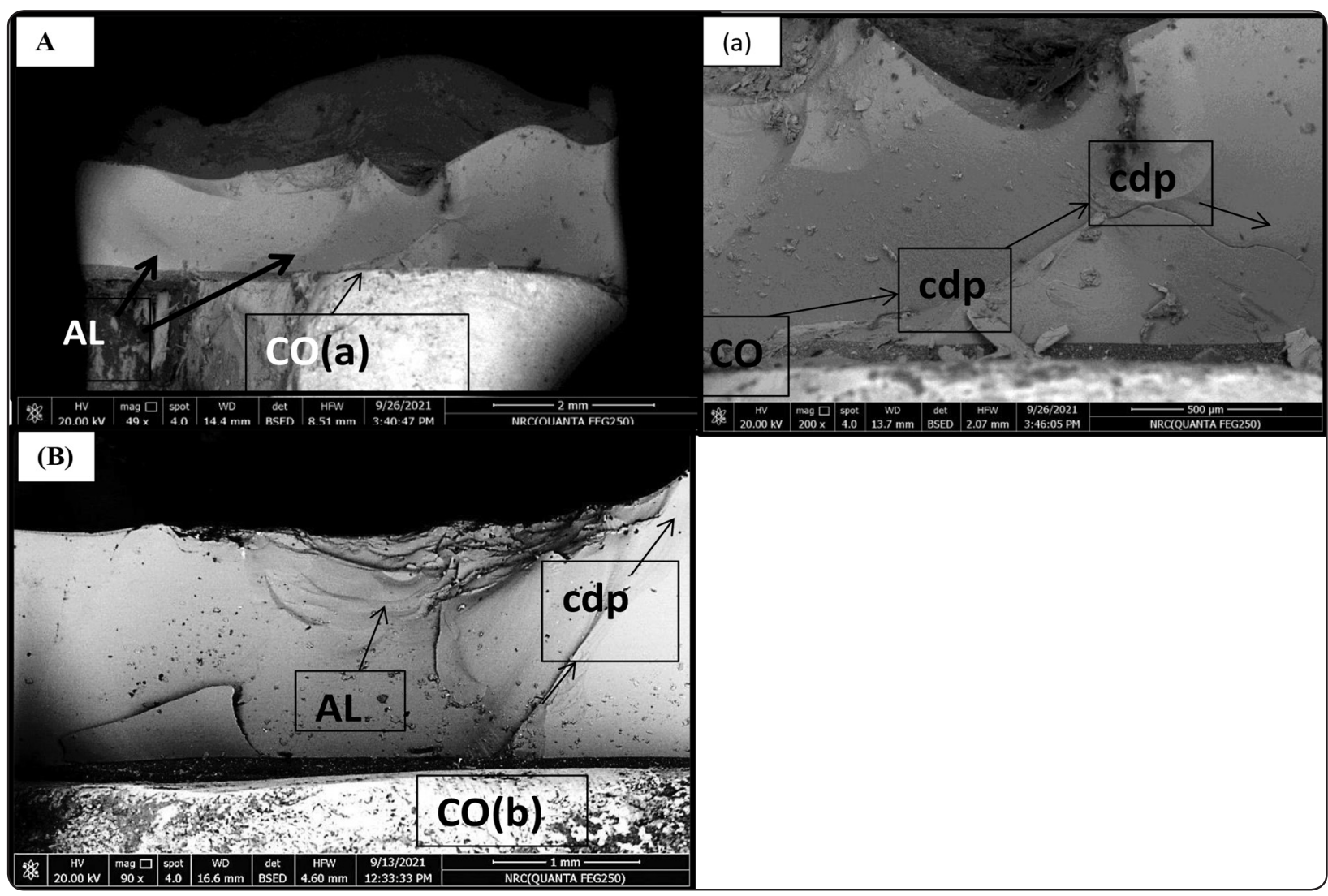

Fig. (8): (A): SEM phtograph of the fractured surface of VS occlusal veneer with $1.00 \mathrm{~mm}$ occlusal thickness. Showing radial crack origin CO (a). AL: arrest lines (different arced arrest lines). a) SEM image of 200x magnification of radial crack origin in (A) showing the radial crack origin, black arrow: crack propagation direction (cdp), originated at the cement interface and propagated in the direction of the proximal margins.

(B): SEM photograph of the fractured surface of VS occlusal veneer with $1.5 \mathrm{~mm}$ occlusal thickness. Showing radial crack origin (b) originated at the cement interface and propagated occlusally. (AL): various arced arrested line for stopping crack propagation from occlusal surface.

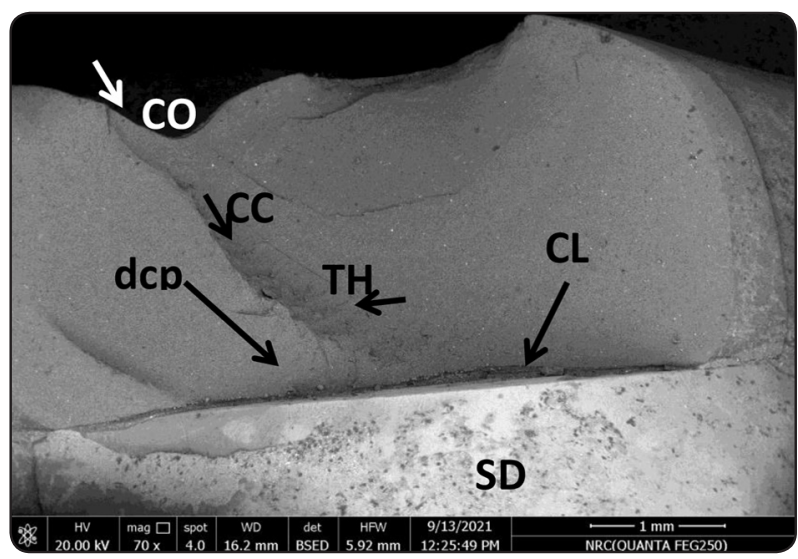

Fig. (9): SEM photograph of the fractured surface of VE occlusal veneer with1.5 mm occlusal thickness. CO: crack origin, where the fracture began, $\mathrm{CC}$ : compression curle, Twist hackle (TL), cracks propagated (direction of crack propagation (dcp). Arrest line (AL), cementation layer (CL), and supporting die (SD). 

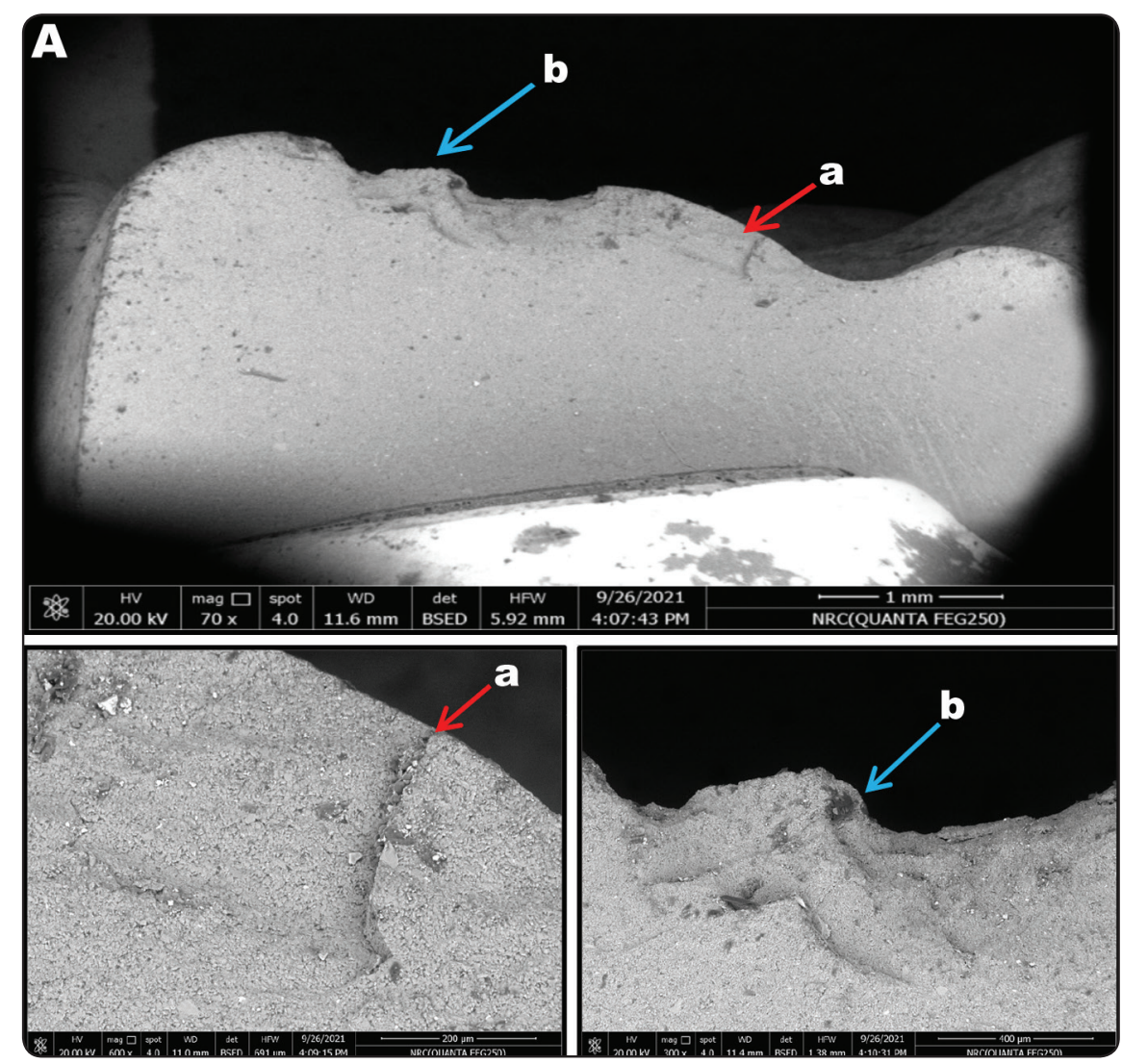

Fig. (10): A): SEM photograph of the fractured surface of VE occlusal veneer with 1.00 $\mathrm{mm}$ thickness showing the fracture origins on occlusal surface (a and b). (a), (b): SEM photographs of magnified crack origins, cracks were stopped within the deep occlusal surface.

\section{DISCUSSION}

This investigation was carried on to evaluate the effect of different CEREC monolithic materials (UP.Cad, Vita Suprinity and Vita Enamic) and different thicknesses $(1.00 \mathrm{~mm}$ and $1.5 \mathrm{~mm})$ on the fatigue resistance of occlusal veneers. According to the results of the present study, the different CAD/ CAM materials and different occlusal thicknesses significantly affected the fatigue resistance of posterior bonded occlusal veneers, so the null hypothesis was rejected.

Conservation of remaining tooth structure is an important aspect of restorative dentistry. Occlusal veneers have been proposed as a conservative substitute for onlays and full-coverage crowns in the management of extensive erosive and/or abrasive defects. ${ }^{(2,3)}$

In the present study, human natural teeth were selected due to their natural elastic characteristics, bonding capability and strength that better matching the clinic situations. ${ }^{(15)}$

CAD/CAM technology was chosen in this study because of its ability to control thickness and geometry of the restorations during fabrication process, it also provides standardized construction technique avoiding laboratory dissimilarities. ${ }^{(16)}$

Two thicknesses were selected in the present study to compare the ideal thickness for posterior ceramic restorations $(1.5 \mathrm{~mm})$ which suggested by the manufactures with a minimally invasive thickness of $1.0 \mathrm{~mm}$.

All selected molars were sectioned by isomet 4 $\mathrm{mm}$ above the (CEJ) to create straight and smooth occlusal surface preparation; ${ }^{(9,17)}$ that retains the cuspal inclination as constant as possible. This preparation design was selected to display the clinical situation of sever tooth wear. ${ }^{(18)}$ 
Repeated occlusal loading during function leads to fatigue failure of dental restorations. ${ }^{(19)}$ Therefore, fatigue resistance of occlusal veneers was evaluated to simulate clinical conditions. This test firstly implemented by previous studies ${ }^{(20,21)}$ and used in several researches. ${ }^{(16,19)}$ Since most failures happened intraorally as a results of fatigue cycles not by constant compressive load. ${ }^{(16)}$

In the current study, there was a statistically significant difference between fatigue resistance mean values of all tested materials, irrespective to occlusal thickness; $(\mathrm{P}=0.0003<0.05)$ as indicated by two-way ANOVA; where VS recorded the statistically highest mean value, followed by UP.Cad while VE presented the least statistically mean value. This finding agreed with previous studies. ${ }^{(22,23)}$ Al-Akhali et al ${ }^{(22)}$ evaluated the effect of thermodynamic loading on the durability and fracture resistance of occlusal veneers constructed from different CAD/CAM materials; E.max CAD, Vita Suprinity, Vita Enamic, and PMMA (Telio CAD). Authors found that Vita Suprinity and E.max CAD veneers recorded significantly higher fracture resistance than Vita Enamic and Telio CAD occlusal veneers. The reasons behind such results might be attributed to the differences in the microstructure, mechanical properties and chemical composition as reported by previous studies. ${ }^{(24,25)}$ Authors clarify the following explanations; first: The dispersion of (10\%) Nano sized zirconia in the homogenous fine glassy matrix of VS improved the fracture resistance and fracture toughness compared with lithium disilicte. ${ }^{(24)}$ The incorporated zirconia increased the fracture toughness by stopping crack propagation. (25) This explains the results of a SEM seen in figure (8) which displayed discrete semicircular arrest outlines around the failure origin occlusally presented in VS occlusal veneers. Second: The VS has a lower modulus of elasticity $(70 \mathrm{GPa})$ than that of Lithium disilicate (95 GPa) which supports that stresses collected in the VS occlusal veneers are less than that collected in Lithium disilicate. ${ }^{(25)}$
However, V Enamic occlusal veneers recorded the least fatigue resistance mean value in both occlusal thicknesses and this might be attributed to the relatively low mechanical properties of this material including low flexural strength (150-160 MPa) and low fracture toughness (1.5 MPa m1/2). ${ }^{(22,24)}$ Another possible factor may be due to microcracks in the network boundaries formed during grinding and polishing process of this hybrid material which composed of crossed networks of ceramic and polymer; which makes different rates of splitting between ceramic and polymer during finishing process, this is assumed to decrease the mechanical properties of the material. ${ }^{(26-28)}$

Interestingly, the current study displayed that an increase in occlusal veneer thickness from 1 to $1.5 \mathrm{~mm}$ significantly affected the fracture strength of all tested materials; $(\mathrm{P}=0.0005<0.05)$ as where $1.5 \mathrm{~mm}$ veneer thickness recorded higher fatigue resistance than $1 \mathrm{~mm}$ indicated by two-way ANOVA. These findings agreed with previous studies. ${ }^{(29-32)}$ Choi et al ${ }^{(29)}$ evaluated the fracture resistances of monolithic crowns constructed from different CAD/CAM using LD, Celtra duo (CD), VS and V.E with different tested occlusal thicknesses, authors found that increase restoration thickness significantly affect fracture resistance. Seghi et al (30) reported that the fracture resistance increased significantly with increase veneer thickness as well as reduced occlusal thickness affected negatively the mechanical properties of the materials; their explanation was due to increased thickness leads to increase tensile stress absorption while thinner thickness leads to higher stress concentration on the cementing interface. ${ }^{(31)}$ Authors supported these results by the finite element analysis (FEA) study ${ }^{(32)}$ who evidently reported that; a variation in ceramic thickness influences the stress distribution. Other studies ${ }^{(33-34)}$ conflict with the findings of the present study, as they found a significant improvement in the survival probability of ceramic restorations with adhesive cementation techniques irrespective to 
the material thickness they explained that superior adhesion can support structural reinforcement. Bakeman et al. ${ }^{(33)}$ reported that ceramic thickness changes have minimal effect on the total flexural strength of the material; authors suggested that effective bonding to the tooth structure allows decreasing to $1 \mathrm{~mm}$ thickness for LD restorations. However, these evidences were not corroborated by the current study, since, even adhesively cemented in extremely standardized, reproducible and controlled procedures, reduced ceramic occlusal veneers presented lower fatigue resistance loads.

Results of the present study concerning the 1.00 mm occlusal veneer thickness recognized that; the highest mean \pm SD values were recorded for $\boldsymbol{U P}$.C $\boldsymbol{C a d}$ group; (1313.2 $\pm 24.7 \mathrm{~N})$ followed by $\boldsymbol{V S}$ group $(1253.8 \pm 8.5 \mathrm{~N})$ whereas; the least were recorded for $\boldsymbol{V E}$ group; $(991.5 \pm 129.7 \mathrm{~N})$. Statistically significant difference was detected between the groups as revealed by ANOVA test $(\mathrm{p}=<0.0001<0.05)$. These results agreed with the results of Sieper et al. ${ }^{(19)}$ who evaluated the effect of different CEREC materials; (LD, ZRL and (PICN)) with different occlusal thicknesses and chewing simulation on the fracture resistance of the crowns. Authors found that LD achieved the highest fracture strength followed by ZLS and PICN recorded the least values at the same thickness, they added that the fracture strength of LD crowns significantly improved after chewing simulation.

Regarding to UP.Cad occlusal veneers it was found that $1.5 \mathrm{~mm}$ occlusal thickness recorded significantly higher fatigue resistance than $1.00 \mathrm{~mm}$; these results conflict with those of Sorrentino et al ${ }^{35)}$ who found that $1 \mathrm{~mm}$ occlusal thickness of LD crowns recorded higher fracture resistance than both thicknesses tested 1.5 and 0.5 ; authors stated that the LD crowns with $1 \mathrm{~mm}$ occlusal thickness guarantee the highest mechanical performances under function in posterior area. Authors described these results to the point that; less bulk of ceramic
$(0.5 \mathrm{~mm})$ transmitted more stresses that absorbed by the resin cement, while, with increased thicknesses of glass ceramics $(1.5 \mathrm{~mm})$, the stress adsorbing capability of resin cements can't be totally effective consequently more intrinsic microcracks in lithium disilicate causing clinical failures. However, this outcome is consistent with results of recent study (28) Anrade et al ${ }^{(28)}$ reported that the most affected material by decreasing occlusal thickness to 0.6 mm was IPS Emax Cad. Authors clarified that; the highest flexural strength $(360 \mathrm{MPa})$ of this material has been reached with $1.5-\mathrm{mm}$ thickness. On the other side Ioannidis et al ${ }^{(36)}$ and Maeder et al. ${ }^{(37)}$ reported that $1.0 \mathrm{~mm}$ thickness of LD occlusal veneers shown fracture resistance values comparable to full-coverage crowns.

Concerning VE occlusal veneers it was found that $1.5 \mathrm{~mm}$ occlusal thickness recorded significantly higher fatigue resistance than $1.00 \mathrm{~mm}$. This result is coincident with the outcomes of Rosentritt ${ }^{(38)}$ and Weyhrauch ${ }^{(39)}$ who tested the fracture resistance of several CAD/CAM fabricated all ceramic implant supported posterior crowns. Authors found that VE registered statistically significant higher fracture resistance values at $1.5 \mathrm{~mm}$ occlusal thickness. On the other hand, this result is inconsistent with the results of previous studies. ${ }^{(19,28,36)}$ Johnson et al. ${ }^{(19)}$ and Andrade et al. ${ }^{(28)}$ reported that changes in occlusal veneer thicknesses of VE were not significantly affect the fracture resistance. This difference might be ascribed to methodologies differences that static compressive loading test was performed rather than fatigue resistance test used in the present study. Ioannidis et al. ${ }^{(36)}$ found that changes in occlusal thickness of VE (0.5 and 1.0 $\mathrm{mm}$ ) were not significantly affected the fracture resistance of occlusal veneer. These dissimilarities might be due to the bonded occlusal veneers to enamel substrate in the previous study ${ }^{(36)}$ which lead to strong adhesion rather than bonded to dentin in the present. In the current study, the teeth were prepared to simulate a clinical progressive teeth wear with dentin exposure. 
In the present study, it was found that an increase in occlusal thickness of VS to $1.5 \mathrm{~mm}$ lead to significantly increase in fatigue resistance than $1.00 \mathrm{~mm}$. This result conflicts with the result by Bergamo el al ${ }^{(40)}$ who evaluated the failure mode of zirconia-reinforced lithium silicate (ZLS) molar crowns with different thicknesses $(0.5 \mathrm{~mm}$, $1.00 \mathrm{~mm}$, and $1.5 \mathrm{~mm}$ ). Authors found that no significant difference was observed between $1.0 \mathrm{~mm}$ and $1.5 \mathrm{~mm}$ crowns. While a significantly decrease in fracture resistance of $0.5 \mathrm{~mm}$ occlusal thickness. This difference might be due to the difference in the testing method and the substrate used; that an epoxy die was used in previous study rather than natural teeth in the present study.

Regards to failure patterns, most of the failures in the present study were repairable patterns. These results came in accordance with previous studies. $(16,21)$ Authors explained these results due to the fatigue resistance methodology used; they reported low percentage of catastrophic failures that cracks were limited to the restorative material. Authors explained the most failures arise in the oral cavity are caused by cyclic fatigue and not by a constant compressive load, consequently, fatigue resistance test delivers more reliable results for investigating the restoration resistance. ${ }^{(16,21)}$

The fracture origins in UP.Cad and VEnamic veneers with both thicknesses ( 1 and $1.5 \mathrm{~mm}$ ) were started in the area of loading contact occlusally, propagated toward the cervical area. The hackles observed below the surface demonstrated that the cracks started from the occlusal surface and grew deeply into the inner surface following the applied loads in the perpendicular direction. The arrest lines were present in the form of ridges on the fracture surfaces, indicating the joining of the cracks at this intersection as seen in (Figure 6,7). These results agreed with the results of previous studies. ${ }^{(29,40)}$

It is well-intentioned that VE with both occlusal thicknesses presented the most favorable frac- ture pattern with no catastrophic failure; this might be explained by the combination of elastic modulus and high resilience of this polymer infiltrated ceramic material $(12.8 \mathrm{GPa})$ which is comparable to that of natural dentition (5.5-19.3 GPa). Elastic modulus of the restoration affects its fracture susceptibility, VE material has more compatible elastic modulus with tooth structure subsequently distribute stresses evenly and tend to bend under load. ${ }^{(41)}$ Presence of the polymer matrix within the VE material tested gives elasticity to the material, hinder the crack propagation by polymer deformation across the crack; and representing this pattern of cracking; that crack propagations was stopped inside the deep occlusal surface as seen in SEM (Figure10). This phenomenon is known as the Dugdale effect where polymer chains in the polymer phase spread plasticity under load as claimed by previous studies. ${ }^{(42,43)}$ Conversely, UP.Cad and VS veneers in the present study revealed $20 \%$ and $40 \%$ catastrophic failure for $1 \mathrm{~mm}$ and $1.5 \mathrm{~mm}$ respectively; yet these rigid glassceramic yield stress concentration at critical areas that might be a reason of catastrophic fractures. ${ }^{(44)}$

On the other side, radial cracks were originated from the cement interface of VS samples, propagated in the direction of the proximal margins or occlusally regardless to the occlusal thickness as shown in SEM (Figure 8). Such failure mode agrees with previous studies. ${ }^{(45,46)}$ Ramos et al ${ }^{(46)}$ evaluated the stress distribution in a monolithic VS crowns by finite element analysis and verified a tensile zone on the cementation interface that confirms the crack origin. Authors reported that failure pattern would not differ with different occlusal thicknesses as bulk fracture included the prime failure mode.

All of the bonded occlusal veneers, regardless of the occlusal thicknesses, recorded values above normal posterior biting forces which valued $424 \mathrm{~N}$ for women, $630 \mathrm{~N}$ for men and $1000 \mathrm{~N}$ for individuals with parafunction. ${ }^{(47)}$ Therefore, these results are within the clinically accepted limit. 
There were limitations for the current study; as the high stiffness of the steel ball used in the instron machine because it does not accurately represent the real oral conditions and further clinical investigations are essential before their general clinical practice.

\section{CONCLUSIONS}

Within the limitations of the present study, the following conclusions can be withdrawn:

1. Material type and occlusal thickness changes affected significantly the fatigue resistance of occlusal veneers.

2. Occlusal veneers fabricated from UP.Cad, VSuprinity and VEnamic blocks with $1.00 \mathrm{~mm}$ and $1.5 \mathrm{~mm}$ thicknesses, demonstrated fatigue resistance values above normal posterior masticatory forces. Hence, the durability of the tested $\mathrm{CAD} / \mathrm{CAM}$ materials seems promising also in an occlusal thickness of $1.0 \mathrm{~mm}$.

3. Occlusal veneers constructed from Vita Suprinity CAD and Vita Enamic blocks yielded promising fatigue resistance compared to UP.Cad blocks.

\section{ACKNOWLEDGEMENT}

The author would like to thank Ivory Trade International Co. the dealer for Upcera Company in the Egyptian market for supplying UP.Cad blocks for this research.

\section{REFERENCES}

1. Lussi A. Hellwia E. Ganss C. Jaeggi T. Bunocore Memorial Lecture. Dental Erosion. Oper Dent. 2009; 34: 245-62.

2. Moslehifard E, Nikzad S, and Geraminpanah F. Fullmouth rehabilitation of a patient with severely worn dentition and uneven occlusal plane: a clinica report. J Prosthodon't. 2012; 21: 56-64.

3. Schlichting LH, Resende T H, Reis K R, and Magne P. Simplified treatment of severe dental erosion with ultra- thin CAD/CAM composite occlusal veneers and anterior bilaminar veneers. J Prosthet Dent. 2016; 116: 474-482.

4. Beuer F, Schweiger J, Edelhoff D.: Digital dentistry: an overview of recent developments for CAD/CAM generated restorations. Br Dent J. 2008: 204: 505-11.

5. Coldea A, Swain MV, Thiel N. Mechanical properties of polymer-infiltratedceramic- 5network materials. Dent Mater. 2013; 29: 419-26.

6. Della Bona A, Corazza PH, Zhang Y. Characterization of a polymer-infiltrated ceramic-network material. Dent Mater. 2014; 30: 564-9.

7. Schwindling FS, Rues S, Schmitter M. Fracture resistance of glazed, full-contour ZLS incisor crowns. Journal of Prosthodontic Research. 2017; 61(3):344-349.

8. Eman Albelasy, Hamdi H. Hamama , James K.H. Tsoi , Salah H. Mahmoud . Influence of material type, thickness and storage on fracture resistance of CAD/CAM occlusal veneers 2021 ; 119:104-485.

9. Egbert, J.S., Johnson, A.C., Tantbirojn, D., Versluis, A.: Fracture strength of ultrathin occlusal veneer restorations made from CAD/CAM composite or hybrid ceramic materials. Oral Sci Int. 2015; 12 (2), 53-58.

10. Sasse, M., Krummel, A., Klosa, K., Kern, M.: Influence of restoration thickness and dental bonding surface on the fracture resistance of full-coverage occlusal veneers made from lithium disilicate ceramic. Dent. Mater. 2015; 31 (8), 907-915.

11. Nicholas T: High Cycle Fatigue - A Mechanics of Materials Perspective. Elsevier Eds, 1st Edition. 2006.

12. Guess, P.C., Schultheis, S., Wolkewitz, M., Zhang, Y., Strub, J.R.: Influence of preparation design and ceramic thicknesses on fracture resistance and failure modes of premolar partial coverage restorations. J. Prosthet. Dent. 2013; 110 (4), 264-273.

13. Ramos ND C, Campos TM, Paz IS, Machado JP, Bottino MA, Cesar PF, et al. Microstructure characterization and SCG of newly engineered dental ceramics. Dent Mater. 2016; 32: 870-8.

14. Furtado de Mendonca A, Shahmoradi M, Gouvea CVD, DeSouza GM, Ellakwa A. Microstructural and mechanical characterization of CAD/CAM materials for monolithic dental restorations. J Prosthodont: 2019; 28:e587-94.

15. Chitmongkolsuk S, Heydecke G, Stappert C. Fracture strength of all-ceramic lithium disilicate and porcelain 
fused-to-metal bridges for molar replacement after dynamic loading. Eur. J. Prosthodont Restor Dent 2002; 10:15-22.

16. Schlichting L, Maia H, Baratieri L, Magne P. Novel-design ultrathin CAD/CAM composite resin and ceramic occlusal veneers for the treatment of severe dental erosion. J Prprosthet Dent. 2011; 105:217-26.

17. Johnson A, Versluis A, Tantbirojn D, Ahuja S.: Fracture strength of CAD/CAM composite and composite-ceramic occlusal veneers; journal of proth. Research; 2014:58:107-114.

18. Egbert J, Johnson A. Tantbirojn D. Versluis A. Fracture strength of ultrathin occlusal veneer restorations made from CAD/CAM composite or hybrid ceramic materials. Oral Sci Int 2015; 2:53-58

19. Sieper K, Wille S, Kern M: Fracture strength of lithium disilicate crowns compared to polymer-infiltrated ceramicnetwork and zirconia reinforced lithium silicate crowns. J Mech Behav Biomed Mater. 2017; 74: 342-348.

20. Fennis WM, Kuijs RH, Kreulen CM, et al.: Fatigue resistance of teeth restored with cuspal-coverage composite restorations. Int J Prosthodont. 2004; 17(3): 313-7.

21. Magne P, Knezevic A: Thickness of CAD-CAM composite resin overlays influences fatigue resistance of endodontically treated premolars. Dent Mater. 2009; 25(10): 1264-8.

22. Al-Akhali M, Chaar MS, Elsayed A, Samran A, Kern M. : Fracture resistance of ceramic and polymer-based occlusal veneer restorations. J Mech Behav Biomed Mater. 2017; 74: 245-250.

23. Bilkhair, Asma : Fatigue Behaviour and Failure Modes of Monolithic CAD/CAM Hybrid-ceramic and All-ceramic Posterior Crown Restorations: Ermüdungsverhalten und Bruchfestikeit Von Monolithischen CAD/CAM HybridKeramik- Materials und Vollkeramischen Restaurationen Im Seitenzahnbereich. Diss. Universität. (2014).

24. Elsaka SE, Elnaghy AM. Mechanical properties of zirconia reinforced lithium silicate glass-ceramic. Dental El Materials. 2016; 32(7):908-914.

25. Zainab M. Jassim and Manhal A. Majeed: Comparative Evaluation of the Fracture Strength of Monolithic Crowns Fabricated from Different all-ceramic CAD/CAM Materials (an in vitro study) Biomedical \& Pharmacology Journal, September 2018Vol. 11(3), p. 1689-1697

26. Presi V, Behr M, Hahnel S, Rosentritt M. Influence of cementation on in vitro performance, marginal adaptation and fracture resistance of CAD/CAM- fabricated ZLS molar crowns. Dent Mater. 2015; 31: 1363-1369.

27. Holand, W., Schweiger, M., Frank, M., Rheinberger V: comparison of the microstructure and properties of the IPS Empress 2 and the IPS Empress glass-ceramics. J. Biomed. Mater. Res. 2000:53, 297-303.

28. Andrade, J.P., Stona, D., Bittencourt, H.R., Borges, G.A., Burnett, L.H.J., Spohr, A.M., CX: Effect of different computer-aided design/computer-aided manufacturing (CAD/ CAM) materials and thicknesses on the fracture resistance of occlusal veneers. Operat. Dent. 2000; 43 (5), 539-548.

29. Choi S., Hyung-In Yoon, and Eun-Jin Park Load-bearing capacity of various CAD/CAM monolithic molar crowns under recommended occlusal thickness and reduced occlusal thickness conditions. J Adv Prosthodont. 2017 Dec; 9(6):423-431.

30. Seghi RR, Daher T, Caputo A. Relative flexural strength ofdental restorative ceramics. Dent Mater; 1990; 6(3):181-4.

31. Kelly JR, Denry I. Stabilized zirconia as a structural ceramic: an overview. Dent Mater. 2008 Mar; 24(3):289-98.

32. Jaiane Bandoli Monteiroa, Hilton Riquieria, Catina Prochnowb,Luís Felipe Guilardib, Gabriel Kalil Rocha Pereirab,c,Alexandre Luiz Souto Borgesd, Renata Marques de Melod,Luiz Felipe Valandrob, Fatigue failure load of two resin-bonded zirconia-reinforced lithium silicate glass-ceramics: Effect of ceramic thickness Dental materials; 2018(34) 891-900

33. Bakeman EM, Rego N, Chaiyabutr Y, Kois JC. Influence of ceramic thickness and ceramic materials on fracture resistance of posterior partial coverage restorations. OperDent; 2015;40(2):211-7.[35]

34. Sasse M, Krummel A, Klosa K, Kern M. Influence ofrestoration thickness and dental bonding surface on thefracture resistance of full-coverage occlusal veneers madefrom lithium disilicate ceramic. Dent Mater2015;31(8):907-15.

35. Sorrentino, Y. Na gasa wa, M. Infelis e, G. Bonad eo, M. Ferrari In vitro analysis of the fracture resistance of CAD-CAM monolithic lithium disilicate molar crowns with different occlusal thickness June 2018; 10(2)Jof osseointegration.

36. Ioannidis, A., Muhlemann, S., Ozcan, M., Husler, J., Hammerle, C.H.F., Benic, G.I., 2019. Ultra-thin occlusal veneers bonded to enamel and made of ceramic or hybrid materials exhibit load-bearing capacities not different from conventional restorations. J Mech Behav Biomed Mater 90, 433-440. 
37. Maeder, M., Pasic, P., Ender, A., Ozcan, M., Benic, G.I., Ioannidis, A., 2019. Load-bearing capacities of ultrathin occlusal veneers bonded to dentin. J. Mech. Behav. Biomed. Mater. 95, 165-171.

38. Rosentritt M, Hahnel S, Engelhardt F, Behr M, Preis V. In vitro performance and fracture resistance of CAD/ CAM fabricated implant supported molar crowns. Clin Oral Investig. 2016 DOI:10.1007/s00784-016-1898-9.

39. Weyhrauch M, Igiel Ch, Scheller H, Weibrich G, Lehmann K M. Fracture strength of monolithic all-ceramic crowns on titanium implant abutments. Int J Oral Maxillofac Implants 2016; 31( 2 ): 304-09

40. Bergamoa, Bordinb D, Ramalhoc S, Lopesc A, Gomesa RS, Kaizerd G M, : Zirconia-reinforced lithium silicate crowns: Effect of thickness on survival and failure mode dental materials ; 2019 (35): 1007-1016

41. El-Damanhoury, H.M., Haj-Ali, R.N., Platt, J.A.: Fracture resistance and microleakage of endocrowns utilizing three CAD-CAM blocks. Operat. Dent. 2015; 40: 201-210.

42. Quinin G, Fractographic Analysis of Broken Ceramic
Dental Restorations: Ceramic Engineering and Science Proceedings · January 2014 .

43. Campos RE, Soares PV, Versluis A, de O Júnior OB, Ambrosano GM, Nunes IF. Crown fracture: Failure load, stress distribution, and fractographic analysis. J Prosthet Dent 2015; 114: 447-55.

44. El Zhawi H, Kaizer MR, Chughtai A, Moraes RR, Zhang Y. Polymer infiltrated ceramic network structures for resistance to fatigue fracture and wear. Dent Mater. 2016 Nov; 32(11):1352-61.

45. Silva NR, Bonfante EA, Martins LM, Valverde GB, ThompsonVP, Ferencz JL, et al. Reliability of reducedthickness andthinly veneered lithium disilicate crowns. J Dent Res2012; 91: 305-10.

46. Ramos GF, Abu-Izze FO, Borges ALS, Anami LC, Bottino MA.Fatigue behavior of ultrafine tabletop ceramic restorations. Dent Mater 2018;34:1401-9.

47. Waltimo, A., Nystr“am, M., K“an“anen, M., 1994. Bite force and dentofacial morphology in men with severe dental attrition. Eur. J. Oral Sci. 102 (2), 92-96. 